\title{
Más allá del malestar. Una hipótesis sociológica sobre el significado político del movimiento estudiantil chileno
}

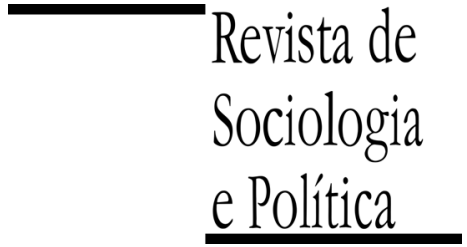

DOI 10.1590/1678-987315235308

\author{
Félix Aguirre y Óscar García Agustín
}

\begin{abstract}
Resumen
La irrupción del movimiento estudiantil chileno requiere ser abordada en clave sociológica. Hasta el momento, la lectura predominante respecto a las tensiones y conflictos que las movilizaciones estudiantiles han dejado emerger se limita a describir cómo las lógicas economicistas de las políticas educativas, impulsadas por los diferentes gobiernos chilenos durante estos últimos treinta años, han provocado un creciente malestar contra el neoliberalismo rampante del que el movimiento estudiantil sería su principal expresión social. Proponemos una hipótesis teórica: el movimiento estudiantil rompe la clausura social establecida por la democracia consensual en Chile. Por medio de este universal polémico el movimiento desafía las políticas de consenso y abre la posibilidad a formas alternativas de concebir la democracia y la participación política. El movimiento estudiantil sintoniza con los movimientos sociales difusos originados en 2011 a raíz de la primavera árabe, tanto en su crítica a la desigualdad producida y reproducida por las políticas neoliberales, como por su naturaleza organizativa horizontal, flexible y participativa. El cuestionamiento del sistema educativo emprendido por los estudiantes pone por primera vez en entredicho el consenso mediante el cual el sistema político chileno ha obtenido su legitimidad durante más de treinta años. A partir de una contextualización sociológica, el artículo propone una hipótesis que permitiría la glocalización del debate sobre el significado político del movimiento; desde temas locales relacionados con la consolidación de la democracia y el deseado desarrollo económico, hacia nuevos temas emergentes donde lo fundamental es dilucidar problemas políticos que hoy parecen universales. Consideramos que en esta confluencia entre lo concreto y lo universal reside la principal novedad del movimiento. Se trata de un movimiento que, en principio, responde a la noción más tradicional del movimiento social, en tanto actor que encauza su lucha hacia objetivos claramente definidos, combinando reivindicaciones de carácter gremial, como la gratuidad de la educación, y de índole política, como la condición pública o privada de la Universidad. Sin embargo, algunas de sus reivindicaciones van más allá del mero anhelo de una sociedad más justa para todos.
\end{abstract}

PALABRAS-CLAVE: movimiento estudiantil chileno; crisis de la Educación Pública en Chile; neoliberalismo; sociología política; globalización.

Recebido em 4 de Julho de 2013. Aprovado em 24 de Setembro de 2013.

\section{Introducción ${ }^{1}$}

${ }^{1}$ Agradezco a los revisores anónimos de la Revista de Sociologia e Política por sus comentarios.
Treinta años después de la implementación de las principales reformas autoritarias en Chile, hoy la financiación privada de la educación proporciona el $51,4 \%$ de todos los recursos del sistema; un caso atípico en la lista de países de la Organización para la Cooperación y el Desarrollo Económico (OCDE), donde el promedio del aporte del Estado a la educación se arrumba al 73,6\% (OCDE 2009). Este experimento educativo condujo a una serie de consecuencias sociales que el movimiento estudiantil ha colocado en la agenda pública. Además de los altos niveles de segregación escolar, que de manera redundante denuncian diferentes organismos internacionales, con municipios endeudados y expuestos a un mercado de incentivos perversos, se ha producido una drástica reducción de la matrícula en las escuelas estatales que imparten enseñanza básica y secundaria. De acuerdo a las proyecciones para el año 2013, el registro municipal representará ya sólo un tercio de la matrícula total del sistema educativo chileno (Waissbluth 2011). Un parámetro que sumado al hecho de que Chile es un país que mantiene uno de los coeficientes de 
${ }^{2}$ Nos referimos, entre otras, a la demanda por el fortalecimiento de la educación pública; a la petición por una mayor transparencia en el uso de los actuales y futuros recursos disponibles para la educación $\mathrm{y}$; a la beligerancia que ha mostrado el movimiento frente al lucro.

\footnotetext{
${ }^{3}$ De acuerdo a los resultados arrojados por un estudio nacional de opinión pública, el Congreso Nacional y los Partidos Políticos, ocupan los dos últimos lugares en un índice que mide la confianza de los ciudadanos en 16 instituciones nacionales. Ver CEP (2010).
}

desigualdad más extremos del mundo (OCDE 2011) apunta a la necesidad de modificar las reglas del juego de manera estructural.

Como sucede en el resto de los niveles del sistema, la progresiva privatización de la educación superior denota también una clara intención política. En Chile los recursos que aporta el Estado para la educación superior equivalen al 0,3\% del PIB, uno de los más bajos del mundo, teniendo en cuenta que el promedio en los países desarrollados es de $1.3 \%$. Considerando que casi la mitad de estos recursos se reparten entre 4 universidades, la mayoría del sistema está endeudado y obligado a lograr su autofinanciación (OCDE 2009). Al mismo tiempo, Chile, en promedio, tiene los sextos aranceles universitarios más caros del mundo, comparado por paridad de poder adquisitivo y un sistema de becas cuya cobertura y dotación es peor que los otros cinco países cuyo arancel es aún más oneroso. Al contrario de lo que ocurre con el sistema universitario de esas mismas cinco naciones, no posee ninguna institución dentro de las catalogadas como de calidad mundial (OCDE 2011), situación que se ve agravada por el hecho de que se trata de un país inserto en un contexto en el que la mayoría de los países sudamericanos puede ofrecer educación gratuita o de muy bajo costo, a pesar que Chile ostenta el mayor PIB per cápita de la zona (Fundo Monetario Internacional 2011). Así, mientras que en 1974 Chile contaba con 8 universidades, conocidas como tradicionales, a las que el Estado aportaba el 86,2\% de su presupuesto basal, en el año 2013, las 25 universidades públicas (estatales y privadas tradicionales) que componen el Consejo de Rectores de las Universidades Chilenas, reciben, en promedio, sólo el 14\% de ese mismo presupuesto (Cuech 2013). Y lo que resulta aún más dramático: en Chile, mientras que el $73 \%$ de la financiación para la educación superior descansa sobre el endeudamiento de las familias, en los países de la OCDE esa cifra se reduce al $16 \%$ (OCDE 2011).

Aunque la mayoría de las reivindicaciones estudiantiles aún no han encontrado eco en la institucionalidad política ${ }^{2}$ en apenas dos años el modelo chileno se ha visto sacudido por un abrupto desperezar político y cultural que parece revestido de un marcado acento anti-neoliberal (Mayol 2012a). Después de treinta años de consensos políticos y macroeconómicos que generaron una sociedad extraordinariamente tolerante respecto a la desigualdad, comienza a instalarse en la opinión pública la percepción de que las desigualdades no son naturales, sino el resultado de relaciones que generan y reproducen el poder en todas sus formas, de manera que las demandas sectoriales del movimiento estudiantil en pos de una educación pública y gratuita han encontrado un respaldo ciudadano transversal (Adimark 2012).

Pese a que la evidencia disponible para valorar el daño infringido a la sociedad por la crisis política, ética e institucional que afecta a la educación estatal es aún muy precaria e incipiente, sí podemos adelantar que buena parte del déficit de autoridad del que adolecen hoy día las instituciones y los liderazgos políticos ${ }^{3}$, se debe a la emergencia de una sociedad mucho menos tolerante frente a la discrecionalidad en el ejercicio del poder y a la extensión de la lógica económica a todas las esferas de la vida social que intervienen en lo que sociólogos y politólogos han convenido en llamar derechos de tercera generación, en especial aquellos que proveen cohesión social y bienestar colectivo, como la educación, la salud y la explotación de los recursos naturales. En términos teóricos, y parafraseando la conocida tesis de Touraine (1997) lo sucedido con el movimiento estudiantil durante estos dos años precedentes ilustra cómo el proceso de construcción de un sujeto con aspiraciones de transformarse en actor puede tener repercusiones dramáticas en la sociedad (idem, p. 210). 
Escrita en clave histórica, la primera sección de este trabajo sintetiza las principales transformaciones sociales de las que se ha ocupado la sociología política durante estos últimos cincuenta años, como un pretexto para insinuar que la irrupción del movimiento estudiantil chileno puede ser abordada en clave sociológica. En la segunda sección sugerimos que el movimiento estudiantil abre la posibilidad de pensar en formas alternativas de entender la democracia y la participación política en el Chile de la post-dictadura. A la espera de la evidencia necesaria para plantear otras preguntas, la hipótesis que proponemos en la tercera sección permitiría describir cómo sintonizan un conjunto de temas locales, relacionados con la consolidación de la democracia y el deseado desarrollo económico, con temas emergentes, donde lo fundamental es dilucidar problemas que hoy parecen universales. En el epílogo subrayamos que el movimiento estudiantil chileno, al asumir la posición de universal polémico, rompe la clausura social establecida por una democracia que ha sido responsable, no solo de la implementación acrítica durante décadas de políticas neoliberales, sino también de un consenso general en torno a otros temas hegemónicos, en particular, aquellos que involucran acuerdos sobre cómo distribuir la riqueza de manera más equitativa y cómo se ha de ejercer la autoridad política en democracia.

\section{La sociología y la política en la sociedad que viene}

Cuando comenzaba la década de 1960 un consagrado sociólogo norteamericano, hasta entonces preocupado por la evolución de la estructura ocupacional norteamericana durante los años 50, publicaba un polémico trabajo que rápidamente se convertiría en referencia obligada para toda una generación de colegas americanos y europeos. Abriendo un largo paréntesis en su meticulosa indagación sobre las transformaciones que se estaban produciendo en la clase media estadounidense, rebautizada por el propio autor con la nominación simpática de trabajadores de cuello blanco, dirigía ahora su reflexión hacia una nueva problemática social que encontraría rápido eco en todos los rincones de la efervescente sociedad del momento: el lugar reservado entonces a la razón y a la libertad, en un momento excepcional, en el que el pensamiento sociológico parecía menospreciar esos dos pilares que habían atravesado la convivencia política occidental desde la Ilustración. Con una disciplina cómodamente sumergida en la moda del empirismo social, medio siglo atrás Wright Mills (1985) nos recordaba que la sociología, además de una técnica, era también una promesa que exigía de nosotros imaginación.

El lamento de Wright Mills ante una sociología ensimismada con un funcionalismo incapaz de plantear con imaginación un diálogo franco con los problemas que entonces parecían atrapar a los actores sociales en su limitada particularidad, cobra especial relevancia en nuestros días, cuando el aumento exponencial del conocimiento del mundo debiera ser una herramienta para permitirnos delimitar marcos de referencia capaces de distinguir la vasta pluralidad de opiniones individuales sobre la vida colectiva de las tendencias sobre el comportamiento social y los grandes problemas públicos que la disciplina tiene el deber de abordar, haciendo uso de todos los recursos metodológicos que posee y, por cierto, de toda su imaginación. El desafío que enfrenta esta imaginación sociológica sigue siendo imponente. Involucra la promesa de ofrecer un argumento racional para usar esta imaginación y tratar de demostrar cómo, a veces, la comprensión de las inquietudes íntimas de un individuo puede estar dramáticamente unida a los problemas sociales. La imaginación que Mills echaba de menos, esa destreza intelectual que ha de servirnos para seleccionar información de calidad y para alumbrar la razón, procurando interpretar los grandes problemas sociales que la historia presente tiene el deber de conciliar 
con las tribulaciones del ciudadano, sigue estando plenamente vigente. Resulta ser el oficio principal de la sociología.

Cuatro décadas después, la teoría sociológica continúa desperezándose del impacto que provocó la caída en desgracia de los grandes relatos (Vattimo, Robatti \& Amoroso 1988). A pesar de las enormes ventajas epistemológicas que nos regaló el desvanecimiento de aquellos imponentes discursos sólidos del pasado, y de que hemos aprendido a bautizar las revoluciones mucho más por las consecuencias y cambios que han provocado en la vida colectiva que por el mero hecho de anunciarse a sí mismas como tales, en nuestros días la sociología discute si la posmodernidad, en vez de haber conducido a una individualización y a una merma en la participación política, puede haber incentivado la emergencia de nuevas formas de expresión ciudadana, que dejan de manifiesto cuan frágiles resultaron ser algunas de las profecías de una escuela empeñada en denunciar la volatilidad de la que entonces hacía gala una nueva cultura política (Wallerstein 2001).

Durante la segunda mitad de la década de los 90 los teóricos de la nueva política anunciaron el declive de los partidos tradicionales y la aparición de nuevos mediadores que estarían al servicio de la gente y no de los políticos, insinuando que el ámbito de la decisión política ya no se reducía al sistema político formal y ortodoxo (Beck, Giddens \& Lash 1997) y que la línea de división típica de las sociedades occidentales, que corría entre izquierda y derecha, se tornaba cada vez más imprecisa, hasta el punto que el conflicto clásico de la sociedad industrial comenzaba a perder la intensidad que había demostrado durante los 60. En particular, la interpretación de Beck (1998) respecto al fenómeno de la reinvención de la política, iluminó el confuso escenario de una disciplina que presentaba su objeto de estudio en referencia a la intersección de tres aspectos claves: la constitución institucional de la comunidad política, los rasgos fundamentales de los programas políticos y los procesos de conflicto político relacionados con el poder. Sin embargo, y aquí la originalidad de Beck, habría un espacio huérfano de conceptualización: el que conforman los agentes externos al sistema político o corporativo. Este era el espacio que él denominó subpolítica. Un espacio que configuraba la sociedad desde abajo y cuyo "instrumento de poder" era la "congestión” (idem, p. 52). La reinvención de la política exigía participación y su recreación demandaba nuevos contenidos, nuevos instrumentos y nuevos objetivos de la política. Para lograrlo, la maquinaria pesada y lenta del Estado debía desprenderse de una imagen arcaica que equiparaba a la sociedad con el cuerpo humano, pues la política de entonces era (¿es?) una política de la vida, cuyos contenidos emanaban de los procesos de autorrealización en contextos pos tradicionales (Giddens 1991).

También durante los 90, una prolija literatura describía la renovación ideológica de los Nuevos Movimientos Sociales (NMS), su remozada base social, sus motivaciones para participar, las nuevas estructuras organizativas y el rápido afianzamiento de un estilo político renovado (Tarrow 1997). Mientras que en las sociedades industriales se conformaban movimientos sociales reconocibles en torno a causas de carácter político y/o laborales, por lo que sus ideologías -al contrario de lo que ocurría en el Antiguo Régimen donde las revueltas eran explosiones de violencia sin una proclama discernible-giraban en torno a un conjunto de ideas que fueron tierra fértil para el movimiento socialista en las postrimerías del siglo $\mathrm{XX}$, los nuevos movimientos sociales conformaban una amalgama mucho más diversa de intereses, urbanos, ecológicos, feministas, étnicos, regionales y sexuales, que parecían coincidir en un pragmatismo ideológico imposible de calificar y en una nueva forma de concebir el espacio público. Quien conformaba la base de social de estos movimientos ya no era la clase obrera, pues las motivaciones para participar en 
estas nuevas formas de acción colectiva parecían ser mucho más altruistas que sus predecesoras. En estas organizaciones se privilegiaba alcanzar un mayor espacio de libertad antes que transformar la estructura global de la sociedad. Frente a la verticalidad que presidía las instancias de participación del partido o el sindicato, las estructuras organizativas en los NMS privilegiaban las formas democráticas, descentralizadas y abiertas (Dalton \& Kuechler 1992), revalorizando la protesta como estrategia política, especialmente aquellas formas ingeniosas e imaginativas que les permitían posicionarse en los medios de comunicación y de estar presentes en la retina de la opinión, extendiendo los derechos democráticos del dominio clásico de la economía a otra serie de relaciones sociales donde también se encuentra presente la subordinación.

Puede que sintamos incomodidad por carecer de un nombre apropiado para bautizar esta sociedad que viene, pero de lo que no hay duda es que la política está de vuelta. Una política a la búsqueda de un equilibrio entre el necesario eclecticismo posmoderno y la obligación de abordar algunas grandes interrogantes de la historia del pensamiento político, en la convicción que para desmontar un Olimpo conceptual como el moderno, preñado de términos tan imaginativos como "Estado", "mercado", "progresso" o "razón", necesitaremos algo más que ídolos que apelen a la globalización o al ocaso de las ideologías. Hablamos de esa política que nunca debiera haber perdido la virtud de ser percibida por la opinión pública como una promesa enmarcada en un discurso que valora la realidad, y, en cuanto tal, hacer gala del pluralismo ideológico necesario para presentarnos distintas proyecciones sobre el acontecer social, desafiando nuestra imaginación cuando nos invita a ejercer el derecho de elegir entre opciones distintas. Pero, indudablemente, la política también es algo más que una manera implícita de concebir el orden social, que conlleve alguna apuesta ética acerca de la naturaleza humana y algún tipo de convicción moral que justifique permanentemente el comportamiento de quien la ejerce. La política es también un procedimiento que cada día presta más atención a los medios empleados por cada opción ideológica para alcanzar y mantenerse en el poder, fortaleciendo el control normativo de la reglamentación de los sistemas políticos y exigiendo de la sociedad una reflexión profunda sobre el papel que le asignamos a los diferentes actores que interactúan en la vida pública.

Volver a pensar la política en los términos descritos nos lleva a reconocer que a pesar de que un número creciente de Estados se viste con ropaje democrático, los entresijos de sus sociedades apenas camuflan un conjunto de paradojas inquietantes; que la eficacia de la democracia como una forma nacional de organización política se ve puesta en duda debido a los cambios constantes en el orden internacional (Dahrendorf 2005); que la crisis de los partidos políticos en las democracias modernas, mediadores que cada día encuentran más dificultades para representar y agregar intereses sociales, parece descansar en el clamoroso divorcio que puede apreciarse entre las nuevas necesidades sociales y las utilidades que el partido procura a una elite interna que se comporta como una verdadera oligarquía (Inglehart \& Welzel 2005); en fin, que tenemos el imperativo moral de redefinir los alcances y límites del poder de influencia del Estado y de la sociedad, a la luz de la emergencia de nuevos actores y movimientos sociales, que nos recuerdan diariamente, con sus diferentes expresiones, la pérdida de eficacia de muchas fórmulas trasnochadas de gestión del poder económico y social, ante un orden que despereza, lenta, pero inexorablemente, la movilización de un público muy poco dispuesto a tolerar cualquier atisbo de corrupción o nepotismo en la clase política y en las elites económicas (Tilly \& Tarrow 2007).

Como sucedió en 2008. A poco de comenzar a conocerse las razones que explicaban el desplome financiero, se anunció que muchas cosas cambiarían. 
Que el capitalismo volvería a ser domesticado con regulaciones; que la democracia debía estar por encima del corporativismo que nos gobierna, la política por delante de la economía y el bienestar por encima de los intereses de los mercados financieros. Que era una falacia sostener que la economía opera con independencia de las voluntades individuales y que, para poder cumplir con la función de generar la riqueza necesaria para garantizar la independencia de las naciones, los mercados requieren de acuerdos colectivos, mediaciones y controles, llamados a recordarnos que para muchos ciudadanos la autonomía que toda persona requiere para su libre desenvolvimiento se garantiza no sólo porque acceda a convertirse en propietario de bienes, sino porque es, ante todo, "propietario" de derechos (Castel 2006). Tras el remezón de 2008 muchos trataron de volver a la normalidad lo antes posible, pero millones de jóvenes de todo el mundo, desde Estambul a Valparaíso, se obstinan en no olvidar. Y es que aunque el desvanecimiento de la idea de progreso continúa dando forma al imaginario social contemporáneo, la importancia que están adquiriendo las movilizaciones civiles transnacionales nos recuerdan cotidianamente que no sólo se han globalizado las estructuras de dominación, sino que las formas de resistencia han encontrado también un aliado en las expeditas vías de comunicación que nos ofrece la mundialización. Hoy, efectivamente, el intercambio político es de carácter transnacional (Tilly 2004), lo que universaliza las formas de resistencia, a pesar que no exista clase social alguna o sujeto histórico que reivindicar. Hoy presenciamos una polifonía de voces que reivindican sus identidades y sus derechos (Laclau \& Mouffe 1987).

\section{La sociedad sí existe. La cuestión educativa y la clausura neoliberal en Chile}

Las sucesivas reformas de los Estados latinoamericanos durante la década de los 80 y buena parte de los 90, inspiradas en un pensamiento neoliberal que partía de la idea de que los conflictos de los años 60 y 70 mostraban que el esquema político liberal podía tornarse fácilmente incontrolable, lo que perjudicaba la estabilidad de un sistema productivo que era considerado el corazón y motor de la democracia liberal (Huntington \& Nelson 1976), no fueron diseñadas para favorecer las políticas de distribución de poder en la sociedad, sino para sustraer la política de los problemas sociales, disminuyendo con ello los espacios para la participación ciudadana. La progresiva despolitización que implicó este modelo de gobernabilidad que tardíamente se impulsó en América Latina (Prats 2001), mediante la transferencia de las necesidades sociales del Estado al mercado, promovió la separación de la política y la economía, transformando profundamente la naturaleza de un conjunto de servicios públicos a partir de entonces concebidos para canalizar las demandas y necesidades de los consumidores (Avritzer 2003). Esta matriz de gobernabilidad entró en crisis en la mayoría de los países latinoamericanos a fines de la década de los 90, coincidiendo con la aparición de nuevas formas de participación popular y de movilización social que produjeron significativos cambios en la institucionalidad estatal, particularmente en Brasil, Ecuador, Venezuela y Bolivia, donde la emergencia de diferentes formas de acción colectiva logró desafiar a las élites tradicionales, por medio de movilizaciones masivas que tuvieron un impacto significativo sobre lo que -se juzgaba- era una visión estrecha y conservadora de la gobernabilidad (Dagnino, Olvera \& Panchifi 2006).

Como sucede en el resto de los países vecinos, los problemas de que adolece el modelo de desarrollo consolidado en Chile durante casi tres décadas, no son sólo económicos sino, ante todo, políticos, y las deudas pendientes del modelo democrático con la sociedad deben ser también abordados desde esa dimensión. Recordemos que el éxito que conlleva la consolidación democrática apela a la institucionalización de acuerdos capaces de consolidar mecanismos que asienten las bases de la confianza y de un conjunto de reglas que garanticen una 
vasta representación de los diferentes intereses sociales, y que esta capacidad está íntimamente relacionada con calidad de la democracia (O’Donnell 2004), de forma que el acceso a la deliberación de las mayorías posibilite la emergencia de una ciudadanía más integrada, que haga compatible la democratización del Estado con la eficacia de las instituciones políticas (Garretón, Cruz \& Aguirre 2012).

Aunque desde 1990 la cuestión educativa ha constituido uno de los principales debates en la sociedad chilena post dictadura, la movilización de estudiantes secundarios durante 2006, conocida como la revolución de los pingüinos, y, más recientemente, desde 2011, las protestas lideradas por los estudiantes universitarios, constituyen dos hitos fundamentales del mencionado debate. En ambos casos nos encontramos ante la expresión de movimientos sociales en un contexto de democratización, como el chileno, extraordinariamente peculiar, marcado, mutatis mutandis, por un proceso exitoso a la hora de terminar con una dictadura militar al tiempo que lastrado por una Constitución autoritaria, que fija los límites de la democratización política al imponer un conjunto de Leyes Orgánicas que, hasta la fecha y por diferentes razones, apenas han sido modificadas por los sucesivos gobiernos democráticos. El sistema educacional chileno, por tanto, mantiene la impronta con que fue dado a luz en las postrimerías de la dictadura militar, con el propósito de adecuarlo al perfil de una sociedad autoritaria, en lo político cultural y organizada en torno al individualismo y el mercado en lo económico social. A esta visión de sociedad, consagrada institucionalmente en la Constitución de 1980, correspondía una visión de la educación y una estructuración de ella, que ya se anunciaban tanto en las Directivas Educacionales de 1979 como en la legislación universitaria de 1989.

En 2005, tras una movilización de estudiantes secundarios espoleada por el alza en el precio del transporte escolar, el Ministerio de Educación creó una Mesa de Trabajo que funcionó durante todo ese año, conformada por los Centros de Alumnos de enseñanza secundaria de Santiago a la que días después se adhirieron diversos colectivos sociales y políticos. La frustración que provocó en las bases estudiantiles los exiguos resultados de esta instancia de diálogo se tradujo en una extensa ola de movilizaciones que durante el 2006 se tomó la agenda política y mediática del país, a pesar de que esas demandas de ese año eran las mismas que se discutieron de manera estéril todo el año precedente: exigir reformas urgentes en la Ley Orgánica Constitucional de Enseñanza, promulgada durante el último suspiro de la dictadura militar, reclamar la gratuidad del transporte escolar y lograr una ostensible reducción del valor de la inscripción en la Prueba de Selección Universitaria. Sólo nueve meses después y apenas seis días antes de que el Consejo Asesor Presidencial para la Calidad de la Educación, instancia generada para mediar en el conflicto, entregara a la entonces Presidenta Bachelet sus conclusiones y recomendaciones finales, los estudiantes secundarios decidieron retirarse del Consejo y no suscribir el documento final. Horas después los estudiantes universitarios tomarían la misma decisión. En su versión final, el Consejo relativizaba algunas de las demandas del movimiento estudiantil de 2006, como el trato preferencial o igualitario por parte del Estado entre establecimientos subvencionados y públicos; la prohibición de sociedades comerciales dedicadas a la educación o el derecho de un establecimiento a seleccionar por mérito a su alumnado. La tramitación en el Congreso del proyecto para la nueva Ley General de Educación recomendada por el Consejo Asesor Presidencial y su promulgación final, terminó diluyendo las demandas más emblemáticas del movimiento estudiantil que habían sido ampliamente discutidas en su seno. Así, mientras que el proyecto de ley prohibía que organizaciones con fines de lucro ingresaran a la educación, la ley final lo permitía; mientras en el proyecto se contemplaba la 
representación estudiantil en el futuro Consejo Nacional de Educación, en la promulgación se excluía esta posibilidad; y mientras en el proyecto se prohibía la selección de alumnos hasta $8^{\circ}$ año de enseñanza básica, en la ley final lo hacía sólo hasta $6^{\circ}$ año (Garretón et al., 2011).

El 12 de mayo de 2011, la denominada primavera estudiantil chilena comenzó con una manifestación que convocó a unas 20 mil personas en Santiago. Hasta noviembre de ese mismo año, cada demostración pública logró reunir un promedio de 150.000 manifestantes, pero, desde julio las demandas de los estudiantes ya no eran sólo económicas sino también políticas. Apelaban a un Estado verdaderamente protagonista en materia educativa, que entendiera la educación como un derecho social y un pilar para el desarrollo (Drago \& Paredes 2011). Ya en ese momento, los manifestantes criticaban la orientación privatizadora de un modelo que había sido fortalecido y rediseñado por los gobiernos democráticos desde 1990 hasta esa fecha, mediante la aplicación de un conjunto de políticas que continuaban profundizando la brecha que separaba la universidad de la sociedad (Carnoy 1997). A pesar de la apuesta a favor del desgaste del movimiento estudiantil, en ese mismo mes, el gobierno obtuvo en las mediciones públicas la más alta reprobación de su gestión, y, presionado por el clamor estudiantil, se vio obligado a realizar un segundo cambio de gabinete que incluía al máximo responsable de la cartera de educación, lo que no impidió que en agosto la suma de los movilizados se empinase al millón de personas (Garretón, Cruz \& Aguirre 2012).

En una columna de opinión publicada un año después por un matutino chileno de circulación nacional, un conocido politólogo abría el fuego de su argumentación sobre el significado de la inminente elección municipal a la que se abocaba el país, echando mano de una afirmación que al articulista se le antojaba incontestable: "En democracia, los votos pesan más que cualquier marcha" (Navia 2012). A juicio del autor, tras un año en que la política nacional se debatió a la sombra del impacto que provocó en la opinión pública las movilizaciones estudiantiles, finalmente aquella elección del 28 de octubre pondría a cada quien en su lugar: "El día de la elección, la voz de los votos despejará cualquier duda sobre la dirección en la que quiere avanzar el país. Aquellos que se atribuyen la representación de la voluntad popular deberán ser capaces de movilizar votantes, porque el peso de los votos se hará oír más fuerte que cualquier cacerolazo" (idem). Tras reconocer que el gobierno cambió sus prioridades programáticas al sentirse presionado por los estudiantes durante todo el 2011, el profesor universitario apela a quienes justificando las marchas o compartiendo las inquietudes de los manifestantes defienden la idea de que estas expresiones sociales representan "[...] a una ciudadanía activa, politizada y comprometida", para, enseguida, una vez que el lector ya ha percibido que el interés de quien escribe no parece ser la elección de octubre, añadir:

"Un análisis menos militante lleva a cuestionar los efectos de las marchas sobre principios básicos de la democracia [...]. Los estudiantes tienen tiempo y capacidad para marchar. Lamentable, los habitantes de zonas rurales, los enfermos graves o los padres de infantes sin acceso a jardines infantiles no poseen las mismas herramientas para ejercer presión a favor de sus legítimas demandas. Cuando votamos,todossomos iguales. Pero cuando marchamos -hacemos lobbying o ejercemos presión por otros medios- se impone la desigualdad. Nada más desigual que tomar decisiones políticas a partir de cuánta gente participa en una marcha. Nada más igualitario que una elección donde el voto de cada persona -empresario o estudiante, rico o pobre, líder universitario o joven trabajador de un call center- vale lo mismo" (idem).

Horas después del cierre de los colegios electorales, los expertos trataban de explicar a la opinión pública por qué solo cuatro de cada diez chilenos había 
concurrido a sufragar el día anterior y por qué los alcaldes electos no habían logrado superar, en promedio, el respaldo de dos de cada diez votantes de su comuna. La elección municipal, efectivamente, había colocado a cada quien en su lugar, mostrando sin ambages el proceso de cambio que se vivía en la política chilena. No se trata de enrostrar al articulista lo que el politólogo parece ignorar en aquello que atañe a un campo de su disciplina que ha sido objeto de una prolija literatura durante estos últimos treinta años (Tilly 2004), sino de resaltar con un ejemplo cómo se ha ido instalando en ciertos medios de comunicación un estilo en el debate desde la irrupción del movimiento estudiantil y del extraordinario esfuerzo que realizan algunos para reiterar una serie de argumentos pensados con el único propósito de ocultar su ideología a golpe de medias verdades.

El profesor Fernando Atria (2012) se hace eco de una simpática expresión acuñada por el filósofo Harry Frankfurt (2005) para describir algunos síntomas de esta cultura política hegemónica en el Chile post-dictadura, a la que califica como una cultura de la demagogia o de la manipulación de la verdad, y que el mismo Frankfurt denomina Bullshit; argumentos cuyo objetivo no apunta a desentrañar los hechos con los que podemos intentar objetivar los juicios que hacemos sobre la realidad, sino a la pura y simple inversión de la verdad; personajes que, como sugiere el filósofo norteamericano, no son ni honestos ni mentirosos; son, simplemente, manipuladores (idem, p. 36). Y es que, al igual que ocurre cuando desde una lógica estrictamente economicista se impone una visión sobre el tratamiento de la desigualdad que excluye otras dimensiones culturales, en lo relativo al estilo prevaleciente de las políticas públicas, el peso desproporcionado de lo que se llamó la democracia de los acuerdos, impuesto en Chile tras la negociación entre las élites políticas y el trasfondo del veto militar a comienzos de los 1990s, en nada contribuyó al desarrollo político de la sociedad, de forma que las transformaciones institucionales acaecidas desde el retorno a la democracia no fueron acompañadas de las necesarias innovaciones políticas. La persistencia de este resabio autoritario y la sorprendente rapidez con que fue mimetizado por toda la clase política durante la transición, explica, en buena medida, por qué los principales problemas que enfrenta el país suelen ventilarse con la implementación de un conjunto de políticas que, negociadas entre cuatro paredes eluden el debate ciudadano (De La Maza 2005) y cómo esta peligrosa inmadurez institucional se ve reflejada en el prontuario de groseros escándalos que viene acumulando un sistema económico que, dejado a su suerte, cada día parece alejarse más de los valores que dice defender el propio capitalismo (Castells 2009).

Hasta el momento, la lectura predominante respecto a las tensiones y conflictos que las movilizaciones estudiantiles han dejado emerger se limita a señalar cómo las lógicas economicistas impulsadas por los diferentes gobiernos chilenos durante estos últimos veinte años, han provocado un creciente malestar frente al neoliberalismo rampante del que el movimiento estudiantil sería su principal expresión. El sociólogo y académico de la Universidad de Chile, Alberto Mayol (2012b) sugiere que el modelo neoliberal chileno se debate en una suerte de crisis terminal, tras la que se avizora un cambio del paradigma modernizador prevaleciente durante toda la post-transición. Un nuevo tiempo en el que la indignación ciudadana arrasa una y otra vez con las agendas políticas tradicionales, en pugna por redimensionar la relación del ciudadano con las instituciones sociales y políticas. El detonador del malestar, naturalmente, apunta al movimiento estudiantil, pero no es su único síntoma. Desde la oposición a diferentes proyectos energéticos a la toma de una capital regional por una ciudadanía empoderada, pasando por la resistencia de vecinos organizados frente al apetito incontrolado por el suelo urbano del que hacen gala las inmobiliarias, pareciera que la confianza pública en la acción auto- 
${ }^{4}$ Los profesionales del marketing en Chile vienen usando este índice ( $\mathrm{ABC} 1, \mathrm{C} 2$, C3 y E) para facilitar el análisis del comportamiento del público consumidor y poder con ello segmentar los mercados. El resultado es una clasificación de los diferentes grupos socioeconómicos extraordinariamente amplia y subjetiva. reguladora del mercado, verdadero catecismo del neoliberalismo criollo que constituye el baluarte ideológico en el que descansa el estilo de las políticas públicas ensayadas durante estas cuatro décadas, hubiera desnudado la fragilidad, el profundo cuestionamiento y la escasa legitimidad de la que gozan los sistemas institucionales de representación de intereses y demandas del ciudadano. Y sobre todo, la verdadera faz de un Estado contemplativo (cuando no ausente) incapaz de reaccionar salvo cuando las irregularidades, los escándalos y las faltas a la fe pública se tornan en delitos flagrantes.

Las conclusiones de un informe reciente, de título inquietante, elaborado por el Programa de Naciones Unidas para el Desarrollo (PNUD 2012) avala solamente parte de esta hipótesis, aportando además algunos datos empíricos de interés. Y es que, en Chile, la sensación de abuso y desconfianza hacia las instituciones convive -de ahí lo inquietante del título del informe- con la alta satisfacción de la que cada chileno dice gozar en su vida privada. La mayoría considera que hoy su vida es mucho mejor que hace diez años (55\%), y la puntuación promedio de satisfacción con la vida, en una escala de 1 a 10, es de 7,3. Sin embargo, esta satisfacción aparece desigualmente distribuida: mientras el 90 por ciento de las personas del grupo $\mathrm{ABC}^{4}$ se encuentran muy satisfechas con sus vidas, sólo el 56 por ciento del grupo E declara lo mismo. Cuando la mirada se torna transversal, la satisfacción subjetiva aumenta: mientras en 1995 un 58 por ciento de la población se declaraba muy satisfecha o satisfecha, hoy el porcentaje se eleva al 77. Por el contrario, la percepción de la sociedad es no sólo negativa, sino que ha venido empeorando con el tiempo. Así, los encuestados evalúan con una nota promedio de 4,1 sobre 10 las oportunidades que el país entrega a las personas, y en ciertos ámbitos, como la seguridad humana y la participación, Chile obtiene nota roja. Algo similar ocurre con la confianza en las instituciones; mientras en 1995 un 30 por ciento confiaba en las instituciones, hoy solo lo hace un 20 por ciento (idem). Lo que resulta aún más trascendente es que frente a la percepción de que para alcanzar la felicidad la sociedad no importa, el Informe parece demostrar lo contrario: la percepción de un proyecto de vida satisfactorio aparece correlacionado con la estructura social, de modo que todo esfuerzo individual puede resultar inconducente si no encuentra un marco de condiciones sociales que lo estimulen (idem, pp. 16-28).

En lo que sí coincidimos con Mayol (2012b) es en el profundo cuestionamiento que el movimiento estudiantil ha instalado en contra del principal imaginario social que ha llenado de significación social el modus operandi del neoliberalismo chileno. La idea de que la sociedad no es un cuerpo moral, sino un ente puramente relacional, donde la justicia social y el bien común se subordinan ante la que debe ser la primera prioridad perseguida por los poderes públicos, en forma de un crecimiento económico del que todos, en algún momento, se iban a beneficiar (Hayek 1960; Guzmán 1982).

\section{Una hipótesis sobre el movimiento estudiantil como "universal polémico"}

Tras recordar que lo distintivo de un argumento sociológico radica en la pretensión universalista de la que hicieron gala los clásicos al momento de abordar los problemas de su tiempo, Daniel Chernilo y Aldo Mascareño (2005) adelantan algunas razones que explicarían la falta de autonomía de la que ha hecho gala la sociología latinoamericana a la hora de describir las señas de identidad de su propia modernidad, añadiendo que, en nuestros días, los diagnósticos contemporáneos que ensaya la disciplina deben tener en cuenta un hecho ineludible, pues " [...] encuentran sus obstáculos y también sus nuevas perspectivas en ese horizonte normativo último y en esas condiciones estructurales universales que hemos denominado sociedad mundial. Se trata de construir una sociología que encuentre su posición entre lo universal y lo particular y 
batalle para hacer sentido de lo uno a partir de lo otro" (Chernilo \& Mascareño 2005, p. 18).

Para dilucidar la dimensión sociológica del movimiento estudiantil parece, por tanto, necesario plantear si, como de hecho sucede en buena parte del planeta indignado (Antentas \& Vivas 2012), también en Chile podemos rastrear alguna de las señas de identidad de este cosmopolitismo que ha permitido a la teoría social contemporánea reconocer en la sociedad mundial un orden emergente (Archer 1996; Chernilo 2006). Aunque lo global y lo local son, en principio, entidades separadas, es un hecho que en nuestros días muchos rasgos simbólicos de la vida cultural local son expresados y compartidos a escala mundial, de manera que cualquier persona o grupo tiene la capacidad de pensar globalmente y actuar localmente. En su versión dialéctica, el concepto de glocalización fue acuñado para explicar esta interacción entre lo global y lo local (Robertson 2003), en particular con el objetivo de describir cómo las nuevas identidades ya no parecían emerger de entre los estrechos límites que demarcaba el Estado-nación, sino más bien a través de una transgresión sistemática de las tradiciones y como efecto de la imposición de nuevas realidades sociales en el marco de la globalización.

En su crítica de la democracia liberal contemporánea, Mouffe (1999) describe con lucidez hasta qué punto el pluralismo globalizado, aparentemente inocuo, que defienden algunos los teóricos liberales, lejos de haber desparramado más tolerancia y consenso en la sociedad mundial, ha logrado sumergir el papel constitutivo que le corresponde al antagonismo en la confrontación política. Este esfuerzo por remplazar el antagonismo potencial de las relaciones sociales por un ingenuo consenso racional, es lo que la propia autora denomina la evasión de lo político, ante lo que resulta urgente pensar en instituciones que permitan dirimir la hostilidad inherente al antagonismo y transformar el conflicto, que en última instancia no es negado, en un reconocimiento de la pluralidad y de la diversidad. Este re-estructuramiento institucional supone el cambio del antagonismo al agonismo (idem). La ya clásica distinción realizada por Rancière (1996) entre policía y política, abundaba en esta misma idea de consenso, como clausura social, y de disenso, como apertura a nuevos modelos de convivencia y organización política. La noción de policía no se limita al aparato del Estado, sino que se refiere a esa regulación invisible de las relaciones sociales que establece criterios sobre lo que se puede decir o no; sobre quién puede participar en la esfera pública y quién no. Se trata, pues, de un concepto próximo al poder simbólico de Bourdieu (1999): el modo en el que la gente percibe 'naturalmente' el mundo. Es, en otras palabras, el orden legítimo percibido como verdadero e inevitable, que, sin embargo, en su aparente universalidad, oculta la reproducción de intereses particulares (idem). La política, en cambio, según Rancière es:

"[...] la que rompe la configuración sensible donde se definen las partes y sus partes o su ausencia por un supuesto que por definición no tiene lugar en ella: la de una parte de los que no tienen parte. Esta ruptura se manifiesta por una serie de actos que vuelven a representar el espacio donde se definían las partes, sus partes y las ausencias de partes. La actividad política es la que desplaza a un cuerpo del lugar que le estaba asignado o cambia el destino de un lugar" (Ranciére 1996, p. 45).

La política conlleva el reconocimiento de la importancia del antagonismo y del disenso en la conformación del orden social. Es una manera de evitar la desafección de los ciudadanos hacia la política, provocada por el reiterativo énfasis en el consenso. Nuestro interés al resaltar el retorno de la política consiste en la necesidad de tomar distancia de las sociedades basadas en un consenso excluyente y en mostrar el papel que los actores sociales desempeñan en lo que Rancière (idem) denomina la reconfiguración del espacio común. 
Mencionábamos anteriormente cómo el orden legítimo se constituía a partir de una aparente universalidad. Si hasta el momento hemos defendido la importancia del disenso y la pluralidad, el universalismo, en tanto que negación de las particularidades representa, en principio, un problema. A pesar de ello, si bien es cierto que desde la lógica institucional (o desde la policía, según Rancière) el universalismo ha servido para deslegitimar o excluir a determinados actores sociales, también lo es que el universalismo puede ser positivo para los movimientos sociales que aspiran a la inclusión y al reconocimiento. En estos casos, el disenso no deriva en la imposición de unos intereses particulares sobre los intereses de los demás, sino en el rechazo de las relaciones de dominación (y su carácter universal) realizado desde la posición de sujetos particulares. Es decir, ciertos sujetos políticos son capaces de denunciar que la exclusión no sólo se aplica a su grupo, sino a "la negación de la humanidad como tal" (Balibar 2005). Ranciére (1996) llama universal polémico a esta confluencia entre las partes y el universal, mientras que Hardt y Negri (2002) prefieren usar la expresión universal concreto.

Sabemos que los elementos deliberativos se han ido alejando paulatinamente de la representación electoral, y que a ello ha contribuido, tanto la dificultad creciente que encierra precisar el concepto de bien común, dada la extraordinaria heterogeneidad del cuerpo de ciudadanos, como el hecho de que las instituciones legislativas de la democracia han ido concentrando sus esfuerzos en la resolución de problemas derivados de una agenda de gobernabilidad focalizada en promover el ejercicio del poder legítimo de los Estados, en un contexto de sucesivas crisis económicas, lo que suele traducirse en que el ámbito institucional, en muchas ocasiones, es renuente a la inclusión de agendas sobre problemas emergentes. Si a esta limitación de la que adolecen los Parlamentos sumamos la constatación del comportamiento político de una ciudadanía que cada vez vota menos, pero que se asocia más, no puede extrañar que las debilidades de la representación justifiquen que la práctica democrática se escenifique en esas otras expresiones e instancias diferentes a la confrontación electoral que hoy parecen orientar el rumbo de la democracia contemporánea (Eastlund 2011). La pregunta es, por tanto, si la democracia está a la altura de las exigencias que las sociedades contemporáneas demandan de ella, y, en particular, si las críticas y reformulaciones al problema de la representación política pueden tener solución en el animado debate sobre la importancia de la deliberación en la extensión de los valores democráticos que hace posible la constitución de un demos capaz de autogobernarse.

Tras la recuperación del régimen político democrático, los gobiernos de la

${ }^{5}$ La CONCERTACIÓN es el nombre de la coalición de partidos de centro izquierda que, hoy en la oposición, gobernó Chile desde 1990 hasta las últimas elecciones presidenciales de 2010 .
CONCERTACIÓN ${ }^{5}$ fueron instalando un estilo de gobernabilidad que rápidamente mostró una indisimulada indiferencia para desarrollar un debate que aceptara los disensos de forma positiva, de modo que pudieran ser procesados, no para transformarlos en consensos forzosos o superficiales, sino para integrarlos como diferencias positivas y facilitadoras de nuevos debates (Huneeus 2008). Entendida así, la democracia de los acuerdos, responsable de la estabilidad institucional de los 90, corría el riesgo de enmudecer la necesaria discusión sobre nuevos problemas emergentes y espolear un miedo al debate y a declarar una posición disidente, que emergía como fuente de la creciente desafección del ciudadano frente a una clase política que parecía preocupaba -y mucho- de declarar una y mil veces que las instituciones funcionaban, pero que apenas incentivaba la discusión sobre la calidad o las competencias de esas mismas instituciones (PNUD 2002).

Nuestra hipótesis se podría enunciar como sigue: la clausura social establecida por la democracia consensual en Chile, ha favorecido la implementación acrítica durante décadas de políticas neoliberales; el movimiento estudiantil desafía esta visión y el imaginario social que conlleva, y no lo hace sólo para 
mejorar sus condiciones particulares, sino consciente de su aportación a la democratización de todo el país. Por medio de este "universal polémico" el movimiento desafía las políticas de consenso y abre la posibilidad a formas alternativas de concebir la democracia y la participación política.

\section{Conclusiones}

Decía Arendt (2005) que los seres humanos no podemos vivir sin prejuicios, y que no hay ninguna forma societal que, sobre la base de esos prejuicios (en sociología solemos usar el nombre más rimbombante de 'representaciones sociales' e 'imaginarios') admita o rechace una serie de comportamientos. De ahí la importancia de enfrentar políticamente lo que "se dice", "se hace" o "se comenta"; porque la política, entre otras cosas, tiene como deber aclarar esos prejuicios, y porque el pensamiento político se sustenta básicamente en la capacidad que cada uno tiene de juzgar sobre los asuntos comunes. Y es justamente durante las crisis históricas -ella añadía - cuando los prejuicios pierden el equilibrio (idem, pp. 52-59) y comenzamos a dejar de confiar en ellos, porque precisamente es durante crisis cuando pierden su valor legitimador, o para usar una expresión más afortunada, cuando todo lo que parece sólido se desvanece en el aire. Quizás sea ese el motivo por el que los politólogos suelen afirmar que cuando los problemas sociales no se afrontan acaban reapareciendo y que, al contrario de lo que Marx pensaba que sucedía con los grandes hechos y personajes de la historia, la segunda versión suele adquirir una forma mucho más dramática que la primera.

Las vicisitudes por las que ha atravesado la cuestión educativa en Chile durante los últimos años constituyen un extraordinario ejemplo de lo anterior. El impacto político y comunicacional logrado por las reivindicaciones estudiantiles ha provocado un acalorado debate que ha dejado emerger las externalidades de un modelo impuesto por la fuerza y largamente planificado, cuyo origen se remonta al temor que provocó la memoria de una sociedad movilizada, gestada cuarenta años antes en el ambiente universitario de la reforma de los años 60. La cuestión educativa no es, por tanto, uno más de los 'enclaves autoritarios' (Garretón 2007) sino la cara más visible de un modelo de sociedad resultado de la voluntad de una clase política proclive a reproducirlo, de forma que el financiamiento del sistema, las funciones que se le asignan a las instituciones educativas, sus objetivos y el lugar que ocupa en la percepción de la ciudadanía, son el fruto de una voluntad política. Y resulta del todo urgente debatir cómo se dio forma a esa voluntad política, con qué mérito fue impuesta a la sociedad en su conjunto y los efectos que esa voluntad ha provocado en un sistema educativo que, desde las reformas introducidas por la dictadura durante la década de 1980, podría muy bien ser calificado de experimental, pues no existe evidencia que nos permita comparar sus credenciales con otros ejemplos similares, ni en lo que se refiere a su regulación normativa, ni en términos de su modelo de financiación (OCDE 2011).

Pero tampoco debemos pasar por alto que esta nueva movilización estudiantil surgió durante esos intensos meses en que comenzamos a acostumbrarnos a ver diariamente cómo los manifestantes que aparecían en las imágenes de todos los medios internacionales, desde Santiago de Chile a El Cairo o desde Nueva York a Madrid, parecían coincidir en que el mundo no cambiaría por sí solo. Que pocos años atrás, en el imaginario de una cultura dominante como la actual, capaz de mercantilizar todos los discursos y las relaciones sociales, resultaba casi inconcebible que un ciudadano tuviera una idea tan diferente sobre el valor de su propia vida que estuviera dispuesto a superar el miedo a manifestar en público su malestar. Hardt y Negri (2012) hablan del sujeto representado como una de las figuras subjetivas evidenciadas 
por las crisis económicas; un sujeto que desconfía del sistema representativo y aboga por una variopinta gama de acciones dirigidas a alterar sus reglas de juego. El movimiento estudiantil sintoniza con los movimientos sociales difusos (Peirone 2012), originados en 2011, a raíz de la primavera árabe, tanto en su crítica a la desigualdad producida y reproducida por las políticas neoliberales, como por su naturaleza organizativa horizontal, flexible y participativa. Sin un claro horizonte normativo, el movimiento hace suya la aspiración de alcanzar un cambio societal que sólo parece posible a partir del cuestionamiento de la política institucional, insinuando que lo que parece estar en juego es si la educación cumplirá o no un rol insustituible cuando la democracia se concibe como un oficio llamado a orientar el comportamiento social y los procedimientos que regulan las relaciones del poder. Un nuevo público para quien la ética del gobernante, cuando se presenta huérfana de una gramática ciudadana, suele terminar anteponiendo los inconfesables intereses de la burocracia a los principios elementales de una vida democrática, que, en nuestros días, apela tanto a los deberes como a las convicciones. Es por eso que los estudiantes apelan al compromiso ineludible que la educación ha de contraer con la democracia, pero, para desesperación de la clase política, no con cualquier democracia.

En varios momentos de este trabajo hemos calificado el sistema educativo chileno de experimental. El cuestionamiento del sistema educativo emprendido por los estudiantes también puede ser calificado de experimental, al poner por primera vez en entredicho el consenso mediante el cual el sistema político chileno ha obtenido su legitimidad durante más de treinta años. De ahí que cuando los estudiantes reinsertan el conflicto y el disenso como parte natural de la dinámica social, sus demandas no queden restringidas únicamente al ámbito educativo. La crítica a la privatización de la educación deviene en una crítica a la democracia consensual. La esfera educativa, como parte de la esfera social, reproduce la desigualdad estructural del sistema y revela cómo el modelo neoliberal es aplicado (Lazzarato 2012). Por eso, subrayamos que el movimiento estudiantil chileno asume la posición de un universal polémico, dado que sus denuncias no se limitan al grupo afectado, sino a todos los ciudadanos excluidos de la esfera política.

Consideramos que en esta confluencia entre lo concreto y lo universal reside la principal novedad del movimiento. Se trata de un movimiento que, en principio, responde a la noción más tradicional del movimiento social, en tanto actor que encauza su lucha hacia objetivos claramente definidos, combinando reivindicaciones de carácter gremial, como la gratuidad de la educación, y de índole política, como la defensa de la condición pública de la Universidad (Aranda 2000). Sin embargo, algunas de sus reivindicaciones van más allá del mero anhelo de una sociedad más justa para todos. Como apunta Badiou (2012), las revueltas históricas, "[...] señalan la urgencia de la reformulación de la propuesta ideológica, de una idea fuerte, de una hipótesis crucial para que la energía que generan y los individuos a quienes involucra puedan traer [...] una nueva forma de organización, y por lo tanto de la política" (idem, p. 62). Una reformulación que en Chile comienza a escenificarse en expresiones e instancias diferentes a la confrontación electoral, de modo que la preocupación por la deliberación de los asuntos públicos y la inclusión ciudadana, se torna en una arena que va dando forma a una nueva cultura política que comienza a orientar, como en otras partes del mundo, el rumbo de la democracia contemporánea.

Félix Aguirre (felix.aguirreuv.cl) é Doutor em Ciencias Políticas y Sociología pela Universidad Complutense de Madrid (España) e Co-Diretor do Núcleo de Investigación en Cultura Política Contemporánea y Espacio Público de la Universidad de Valparaíso (Chile). 
Óscar García Agustín (oscar@cgs.aau.dk) é Doctor em Ciencias Políticas, Universidad de La Rioja, España e Profesor Titular del Departamento de Cultura y Estudios Globales, Universidad de Aalborg, Dinamarca.

\section{Referências}

Antentas, J.M.; Vivas, E. 2012. Planeta indignado. Ocupando el futuro. Madrid: Sequitur.

Aranda, J.M. 2000. El movimiento estudiantil y la teoría de los movimientos sociales. Convergencia, 7(21), pp. $225-250$.

Archer, M. 1996. Culture and Agency. The Place of Culture in Social Theory. Cambridge (UK): Cambridge University Press.

Arendt, H. 2005. ¿Qué es la política? Buenos Aires: Paidós.

Atria, F. 2012. La mala educación. Ideas que inspiran al movimiento estudiantil en Chile. Santiago de Chile: Catalonia/CIPER.

Avritzer, L. 2003. Democracy and the Public Space in Latin America. Princeton: Princeton University Press.

Badiou, A. 2012. El despertar de la historia. Madrid: Clave Intelectual.

Balibar, É. 2005. Violencias, identidades y civilidad. Para una cultura política global. Barcelona: Gedisa.

Beck, U. 1998. La invención de lo político. Buenos Aires: Fondo de Cultura Económica.

Beck, U.; Giddens, A.; Lash, S. 1997. Modernidad reflexiva. Política, tradición y estética en el orden social moderno. Madrid: Alianza Editorial.

Bourdieu, P. 1999. ¿Qué significa hablar? Economía de los intercambios lingüísticos. Madrid: Akal.-

Carnoy, M. 1997. Is Privatization Through Education Vouchers Really the Answer? A comment on West. World Bank Research Observer, 12(1), pp. 105-116.

Castel, R. 2006. La inseguridad social: ¿qué es estar protegido? Buenos Aires: Manantial.

Castells, M. 2009. Comunicación y poder. Madrid: Alianza.

Chernilo, D. 2006. El rol de la 'sociedad' como ideal regulativo: hacia una reconstrucción del concepto de sociedad moderna. Cinta de Moebio, 21, pp. 175-188.

Chernilo, D.; Mascareño, A. 2005. Universalismo, particularismo y sociedad mundial: obstáculos y perspectivas de la sociología en América Latina. Persona y Sociedad, 19(3), pp. 17-45.

Dahrendorf, R. 2005. En busca de un nuevo orden. Una política de la libertad para el siglo XXI. Barcelona: Paidós.

Dalton, R.J.; Kuechler, M. 1992. Los nuevos movimientos sociales. Valencia: Editorial Alfons el Magnànim.

De La Maza, G. 2005. Tan lejos, tan cerca. Políticas públicas y sociedad civil en Chile. Santiago de Chile: LOM Ediciones.

Dagnino, E.; Olvera, A.; Panchifi, A., eds. 2006. La disputa por la construcción democrática en América Latina. México: Fondo de Cultura Económica.

Drago, J.L.; Paredes, R. 2011. La brecha de calidad en la educación chilena. Revista CEPAL, 104, pp. 167-180.

Eastlund, D. 2011. La autoridad democrática. Los fundamentos de las decisiones políticas legítimas. Madrid: Siglo XXI.

Frankfurt, H. 2005. OnBullshit. Sobre la manipulación de la verdad. Barcelona: Paidós.

Garretón, M.A. 2007. Del postpinochetismo a la sociedad democrática. Globalización y política en el bicentenario. Santiago de Chile: Random House Mondadori.-

Garretón, M. A.; Cruz, M. A.; Aguirre, F. 2012. La experiencia de los Consejos Asesores en Chile y la construcción de los problemas públicos. Revista Mexicana de Sociología, 74(2), p.p. 303-340.

Garretón, M.A.; Cruz, M.A.; Aguirre, F.; Bro, N.; Farías, E.; Ferreti, P.; Ramos, T. 2011. Movimiento social, nuevas formas de hacer política y enclaves autoritarios. Los debates del Consejo Asesor para la Calidad de la Educación en el gobierno de Michelle Bachelet en Chile. Polis, 30, pp. 1-16.

Giddens, A. 1991. Modernity and self-identity. Self and society in late modern age. Stanford: Stanford University Press.

Guzmán, J. 1982. El sentido de la transición. Revista Realidad, 38, pp. 9-28.

Hardt, M.; Negri, A. 2002. Imperio. Barcelona: Paidós. 2012. Declaración. Barcelona: Paidós.

Hayek, F. 1960. The Constitution of Liberty. London: Routledge.

Huntington, S.P.; Nelson, J. 1976. No Easy Choice. Political participation in developing countries. Cambridge (MA): Harvard University Press.

Huneeus, C. 2008. La democracia presidencial en Chile. México: Instituto de Investigaciones Jurídicas, UNAM.

Inglehart, R.; Wencel, C. 2005. Modernization, Cultural Change and Democracy. The human development sequence. Cambridge (UK): Cambridge University Press.

Laclau, E.; Mouffe, C. 1987. Hegemonía y estrategia socialista. Hacia una radicalización de la democracia. Madrid: Siglo XXI.

Lazzarato, M. 2012. The Making of the Indebted Man. Cambridge (MA): MIT Press.

Mayol, A. 2012a. El derrumbe del modelo. La crisis de la economía de mercado en el Chile contemporáneo. Santiago de Chile: LOM Editores. .2012b. No al lucro. De la crisis del modelo a la nueva era política. Santiago de Chile: LOM Editores.

Mouffe, C. 1999. El retorno de lo político. Comunidad, ciudadanía, pluralismo, democracia radical. Barcelona: Paidós.

O'Donnell, G., ed. 2004. La democracia en América Latina: Hacia una democracia de ciudadanas y ciudadanos. Buenos Aires: Programa de Naciones Unidas para el Desarrollo.

Peirone, F. 2012. El año que redefinió la política. Revista de Cultura Ñ, 23 jan. Disponível em: http://www.revistaenie.clarin.com/ideas/Movimientos-sociales-2011-Wall-Street-Tunez-Madrid_0_631736832.html.

Acesso em: 4 fev 2015. 
Prats, J. 2001. Gobernabilidad democrática para el desarrollo humano. Marco conceptual y analítico. Revista Instituciones y Desarrollo, 10, pp. 103-148.

Rancière, J. 1996. El desacuerdo. Política y filosofía. Buenos Aires: Ediciones Nueva Visión.

Robertson, R. 2003. Glocalización: tiempo-espacio y homogeneidad-heterogeneidad, Cansancio del Leviatán: problemas políticos de la mundialización. Madrid: Trotta.

Tarrow, S. 1997. El poder en movimiento: los movimientos sociales, la acción colectiva y la política. Madrid: Alianza Editorial. Tilly, C. 2004. Contienda política y democracia en Europa 1650-2000. Barcelona: Hacer.

Tilly, C.; Tarrow, S. 2007. Contentious Politics. London: Paradigm Publishers.

Touraine A. 1997. ¿Podremos vivir juntos? Iguales y diferentes. Buenos Aires: Fondo de Cultura Económica.

Vattimo, G.; Rovatti, P.; Amoroso, L. 1998. Il pensiero debole. Milano: Feltrinelli.

Waissbluth, M. 2011. Profundizando el 'apartheid' educativo. La Tercera, 26 abr.

Wallerstein, I. 2001. Después del liberalismo. Madrid: Siglo XXI.

Wright Mills, C. 1985. La imaginación sociológica. México: Fondo de Cultura Económica.

\title{
Outras fontes
}

Adimark. 2012. Encuesta: Evaluación de la Gestión del Gobierno. Informe Mensual, Sept. Santiago de Chile.

CEP. 2010. Estudio Nacional de Opinión Pública Proyecto Auditoría a la Democracia 2010. Disponível em: http://www.cepchile.cl/1_4709/doc/estudio_nacional_de_opinion_publica_proyecto_auditoria_a_la_democracia.html\#.VNMBUp3F-So. Acesso em: 2 fev 2015.

CUECH. Consorcio de Universidades del Estado de Chile. 2013. Propuestas para un nuevo sistema de educación superior. Santiago de Chile.

FUNDO MONETARIO INTERNACIONAL. 2011. Estudios Económicos y Financieros. Perspectivas Económicas. Las Américas, vientos cambiantes, nuevos desafíos de política. Washington: FMI.-

Navia, P. 2012. Salen las marchas, entran los votos. La Tercera, 13 ago. Disponível em: https://files.nyu.edu/pdn200/public/LaTercera/LT20120813.htm. Acesso em: 4 fev 2015.

OCDE. 2009. La educación superior en Chile. Paris: OECD. . Education at a Glance: OECD Indicators. Geneve: OECD Publishing.

PNUD. 2002. Informe de Desarrollo Humano. Nosotros los chilenos, un desafío cultural. Santiago de Chile: PNUD. . Desarrollo humano en Chile. Bienestar subjetivo: el desafio de repensar el desarrollo. Santiago de Chile: PNUD.

\begin{abstract}
The irruption of Chilean student movement required to be addressed in sociological terms. So far, the predominant reading regarding the tensions and conflicts that student demonstrations have left to emerge is limited to describe how the economic logic of educational policies, driven by different Chilean Governments for these past thirty years, have caused growing unrest against the rampant liberalism of which the student movement would be its main social expression. We propose a theoretical hypothesis: the student movement breaks the social closure established by consensual democracy in Chile. Through this universal polemico the movement defies consensus policies and opens the possibility to alternate ways of conceiving democracy and political participation. The student movement links with diffuse social movements, originated in 2011, following the Arab spring, both in his criticism of inequality produced and reproduced by neoliberal policies, and organizational nature horizontal, flexible and participatory. For the first time questioning the education system undertaken by students puts in doubt the consensus by which the political system has obtained its legitimacy for more than thirty years. From a sociological contextualization, the article proposes a hypothesis that would allow the glocalization of the debate on the political significance of the movement; from local issues related to the consolidation of democracy and the desired economic development, towards new emerging issues where the fundamental thing is to elucidate political problems that now seem universal. We consider that this confluence between the concrete and the universal lies the main novelty of the movement. It's a movement that, in principle, responds to the more traditional notion of the social movement, as an actor who directs his struggle toward goals clearly defined, combining claims of Trade Union character, such as free education, and of a political nature, as the condition of public or private University. However, some of their demands go beyond the mere yearning for a fairer society for all.
\end{abstract}

KEYWORDS: chilean student movement; crisis of political education in Chile; neoliberalism; political sociology; globalization.

License information: This is an open-access article distributed under the terms of the Creative Commons Attribution License, which permits unrestricted use, distribution, and reproduction in any medium, provided the original work is properly cited. 